\title{
Edukasi Kesehatan Peningkatan Kesejahteraan Penderita Diabetes Mellitus Melalui 3P (Promote, Prevention, and Protect) di Desa Kamarian Kabupaten Seram Bagian Barat
}

\author{
La Rakhmat Wabula*1, Endah Fitriasari², Syahfitrah Umamity ${ }^{3}$ \\ 1,2,3Program Studi Ilmu Keperawatan, STIKes Maluku Husada, Indonesia \\ *e-mail: la.rakhmat.wabula.stikesmh@gmail.com ${ }^{1}{ }_{\text {endahftiriasari1605@gmail.com }}{ }^{2}{ }_{\text {en }}$ \\ syahfitrah.umamity@gmail.com $^{3}$
}

\begin{abstract}
Abstrak
Diabetes Mellitus (DM) telah menjadi ancaman kesehatan masyarakat karena dapat menyebabkan berbagai masalah kesehatan lain dan diprediksi prevalensinya akan terus meningkat di masa mendatang. Terkhususnya prevalensi penderita Diabetes Mellitus di Puskesmas Kamarian dalam kurun waktu Januari-Juni 2021 jumlah kunjungan penderita mencapai 42 kasus. Dari data tersebut, dapat diketahui bahwa penderita Diabetes Mellitus di Desa Kamarian belum pernah terpapar infromasi terkait latihan jasmani senam kaki yang dapat diterapkan pada penderita Diabetes Mellitus sebagai upaya pencegahan komplikasi diabetes pada kaki. Kegiatan pengabdian ini dilakukan dengan tujuan membimbing dan melatih para penderita Diabetes Mellitus dan masyarakat yang berisiko untuk meningkatkan kesejahteraan serta kualitas hidup. Metode yang digunakan adalah bersama dengan mitra yaitu kader kesehatan dan masyarakat, mengidentifikasi kelompok sasaran dan menciptakan home based untuk pusat terapi. Tim kemitraan ini melatih para penderita Diabetes Mellitus dengan memberikan pendidikan kesehatan mengenai manajemen diet Diabetes Mellitus serta senam kaki diabetik. Sebelum kegiatan dilakukan, tim pengabdian melakukan pemeriksaan gula darah sewaktu. Alat pemeriksaan yang digunakan adalah easy touch dan stik, media komunikasi yang digunakan adalah leaflet dan audiovisual. Jumlah peserta dalam kegiatan pengabdian ini adalah 56 orang yang kemudian teridentifikasi pederita Diabetes Mellitus menjadi 42 orang. Hasil kegiatan terdiri dari gambaran hasil gula darah dan tingkat pengetahuan yang meningkat; Peningkatan keterampilan pesreta yaitu mampu melakukan senam kaki diabetik secara mandiri.
\end{abstract}

Kata kunci: Diabetes Mellitus, Edukasi Kesehatan, Pencegahan, Perlindungan, Promosi

\begin{abstract}
Diabetes Mellitus (DM) has become a public health threat because it can cause various other health problems and its prevalence is predicted to continue to increase in the future. In particular, the prevalence of people with Diabetes Mellitus at the Kamarian Health Center in the period January - June 2021, the number of patient visits reached 42 cases. From these data, it can be seen that people with Diabetes Mellitus in Kamarian Village have never been exposed to information related to physical exercises that can be applied to people with Diabetes Mellitus as an effort to prevent complications of diabetes in the feet. This service activity is carried out to guide and train people with Diabetes Mellitus and the community at risk to improve their welfare and quality of life. The method used is together with partners, namely health cadres and the community, identifying target groups and creating a home-based therapy center. This partnership team trains Diabetes Mellitus sufferers by providing health education about Diabetes Mellitus diet management and diabetic foot exercises. Before the activity was carried out, the service team conducted a temporary blood sugar check. The inspection tools used are easy touch and sticks, the communication media used are leaflets and audiovisual. The number of participants in this service activity was 56 people who were later identified as 42 people with Diabetes Mellitus. The results of the activity consist of an overview of blood sugar results and an increased level of knowledge; Improving the skills of participants, namely being able to do diabetic foot exercises independently.
\end{abstract}

Keywords: Diabetes Mellitus, Health Education, Prevention, Promotion, Protect

\section{PENDAHULUAN}

Diabetes Mellitus (DM) telah menjadi ancaman kesehatan masyarakat karena dapat menyebabkan berbagai masalah kesehatan lain dan diprediksi prevalensinya akan terus meningkat di masa mendatang (Suhatridjas, 2020). Prevalensi penderita DM di Provinsi Maluku menurut Data Riset Kesehatan Dasar Provinsi Maluku pada tahun 2018 sebesar 0,75\%. 
Sedangkan prevalensi penderita DM di Kabupaten Seram Bagian Barat sebanyak 0,47\% (Kemenkes RI, 2018). Data Dinas Kesehatan Kabupaten Seram Bagian Barat pada tahun 2018 mencapai 426 penderita. Puskesmas Kairatu memiliki kunjungan penderita DM cukup tinggi di Desa Kamarian. Berdasarkan data dari Puskesmas Kamarian dalam kurun waktu Januari-Juni 2021 jumlah kunjungan penderita dengan Diabetes Mellitus mencapai 42 kasus.

Salah satu komplikasi penyakit DM yang sering dijumpai adalah kaki diabetik yang bermanifestasikan sebagai ulkus, infeksi dan gangrene. Ada dua tindakan prinsip dasar dalam pengelolaan kaki diabetik yaitu tindakan pencegahan dan tindakan rehabilitasi. Tindakan rehabilitasi meliputi program terpadu yaitu evaluasi tukak, pengendalian kondisi metabolic, dibridemen luka, biakan kuman, antibiotika tepat guna, tindakan bedah rehabilitatif dan rehabilitasi medik. Tindakan pencegahan meliputi edukasi perawatan kaki dan sanam kaki (Pratiwi et al., 2020).

Senam kaki merupakan latihan yang dilakukan bagi penderita DM atau bukan penderita untuk mencegah terjadinya luka dan membantu melancarkan peredaran darah bagian kaki (Putri \& Nugroho, 2020). Apabila seseorang terdiagnosa DM maka sangat diperlukan dilakukannya pencegahan primer yaitu dengan perawatan kaki seperti membersihkan kaki, memakai kaos kaki dan tidak berjalan menggunakan alas kaki (Rahmita, 2020). Perawat sebagai salah satu tim kesehatan, selain berperan dalam memberikan edukasi kesehatan juga dapat berperan dalam membimbing penderita DM untuk melakukan senam kaki sampai dengan penderita dapat melakukan senam kaki secara mandiri.

Melakukan perawatan kaki secara teratur dapat mengurangi penyakit kaki diabetik sebesar 50-60\%. Untuk meningkatkan vaskularisasi perawatan kaki dapat juga dilakukan dengan Gerakan-gerakan kaki yang dikenal sebagai senam kaki diabetes (Ekawati Sutikno, Destya Ika Sriwardani, 2018). Gerakan-gerakan senam kaki ini dapat memperlancar peredaran darah di kaki, memperbaiki sirkulasi darah, memperkuat otot kaki dan memperkuat Gerakan sendi kaki. Dengan demikian diharapkan kaki penderita diabetes dapat terawatt baik dan dapat meningkatkan kualitas hidup penderita DM (Prabawati et al., 2021).

Berdasarkan hasil studi pendahuluan terhadap penderita DM di Desa Kamarian didapatkan bahwa sebagian besar penderita mengetahui bahwa DM dapat menimbulkan kompikasi pada kaki, tetapi belum pernah mendengar mengenai latihan jasmani berupa senam kaki untuk penderita DM. Dari data tersebut, dapat diketahui bahwa penderita DM di Desa Kamarian belum pernah terpapar dengan senam kaki pada penderita DM dalam upaya pencegahan komplikasi diabetes pada kaki. Hal inilah yang menjadi tujuan utama dalam kegiatan pengabdian masyarakat ini yakni memberikan pemahaman dan edukasi kepada masyarakat yang ada di Desa Kamarian melalui kegiatan Pengabdian Masyarakat berupa "Edukasi Kesehatan Peningkatan Kesejahteraan Penderita Diabetes Mellitus melalui 3P (Promote, Prevention, and Protect) di Desa Kamarian Kabupaten Seram Bagian Barat".

\section{METODE}

Tahapan kegiatan mulai awal sampai kahir kegiatan pengabdian terdiri dari beberapa tahap. Kegiatan ini diawali dengan survei tempat pengabdian, pembuatan proposal, koordinasi dengan mitra, koordinasi dengan puskesmas, dinas kesehatan, kemudian menentukan target mitra, tim memulai pengabdian. Pada awal pengabdian tim mengkaji data kebutuhan masyarakat dengan Forum Group Discussion (FGD), kemudian merancang model. Selanjutnya setelah mendapatkan pendanaan maka mengadakan pelatihan pada masyarakat dan kelompok terget, mengevaluasi kegiatan, membuat laporan dan presentasi hasil kegiatan.

Melalui kegiatan pengabdian masyarakat ini dicarikan solusi bagi permasalahanpermasalahan yang telah dirumuskan di atas. Pendekatan yang ditawarkan bagi realisasi program pengabdian masyarakat ini adalah model pemberdayaan dengan langkah-langkah yang telah dilakukan sebagai berikut:

a. Tahap I adalah melakukan pre test dengan mengisi beberapa kuesioner yang dipandu oleh petugas (dosen dan mahasiswa) untuk menilai pengetahuan peserta mengenai manajemen 
diet DM dan pentingnya latihan jasmani kaki berupa senam kaki bagi penderita DM.

b. Tahap II adalah pengenalan penderita DM pada masyarakat: pengenalan dan pelatihan tentang manajemen diet DM meliputi: pemahaman tantang tujuan dan perencanaan tindakan yang berkaitan dengan perilaku diet, informasi dasar tentang makanan sehat (gizi seimbang) dan jenis-jenis diet, perhintungan kalori dan pola diet sehat atau perencanaan makan. Pada tahap ini dilakukan ceramah, tanya jawab dan diskusi. Media yang digunakan adalah leaflet, LCD, dan Laptop.

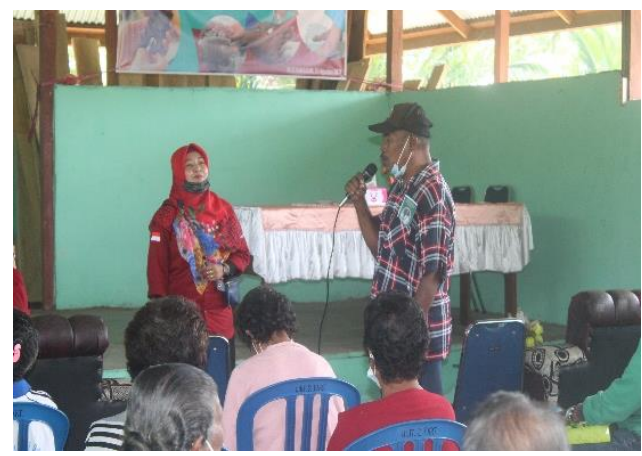

Gambar 1. Edukasi Kesehatan tentang Manajemen Diet DM

Tahap II adalah pelatihan senam kaki diabetik. Alat peraga yang digunakan adalah video dan peragaan gerakan oleh instruktur. Mengajarkan senam kaki sesuai dengan standar operasional prosedur. Senam kaki dilakukan dengan menggunakan alat berupa kursi untuk tempat duduk peserta dan koran bekas. Senam kaki dilaksanakan selama 30-45 menit.

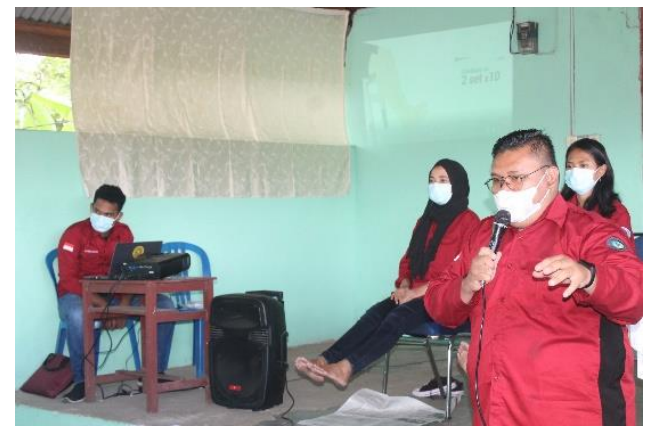

Gambar 2. Pelatihan Senam Kaki Diabetik

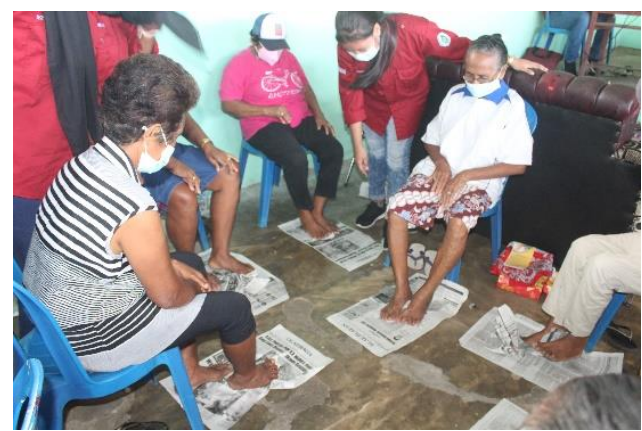

Gambar 3. Peragaan Gerakan Senam Kaki Diabetik

c. Tahap III adalah post test. Evaluasi dilakukan selama proses pelatihan dan follow up sesudah pelatihan selesai. Selama pelatihan, post test dilakukan dengan mengukur tingkat pengetahuan peserta dengan soal tentang DM sebanyak 10 pertanyaan. Soal diberikan sesudah diberikan edukasi kesehatan tentang pengetahuan DM. Evaluasi selama proses juga dilakukan untuk pelatihan senam kaki diabetik yaitu dengan meminta 3 peserta secara acak untuk mengulang kembali gerakan senam diabetik. 


\section{HASIL DAN PEMBAHASAN}

Pengabdian pada masyarakat ini dilakukan pada tanggal 05 Agustus 2021 bertempat di Desa Kamarian Kabupaten Seram Bagian Barat. Kegiatan ini diikuti oleh warga desa beserta kader dan perangkat desa. Sosialisasi seluruh tahapan yang harus dilalui dilakukan pada awal tahap kegiatan. Pada tahap pertama tim pengabdian melakukan pemeriksaan kesehatan pada peserta yang meliputi pemeriksaan gula darah sewaktu. Setelah semua peserta dilakukan pemeriksaan kesehatan peserta diminta berkumpul di Balai Desa untuk diberikan penyuluhan pengetahuan tentang manajemen diet DM. Peserta edukasi meliputi penderita DM di Desa Kamarian Kabupaten Seram Bagian Barat Wilayah Kerja Puskesmas Kairatu. Jumlah peserta sebanyak 42 orang.

\subsection{Kegiatan screening DM}

Setiap warga yang hadir dilakukan pendataan. Meja 1 adalah pendaftaran, dimana warga di wawancara tentang data demografi meliputi nama, alamat, tanggal lahir, jenis kelamin, dan pekerjaan. Menurut Trijayanti (2019) faktor demografi sangat penting untuk dikaji pada penderita DM. kemudian warga pindah ke meja 2 yaitu pemeriksaan tekanan darah, denyut jantung, suhu, dan pernapasan. Menurut Ruben et al (2016) bahwa peningkatan tekanan darah merupakan salah satu bentuk komplikasi dari penyakit DM. Selanjutnya pada meja 3 dilakukan pemeriksaan gula darah, warga dilakukan penusukan jarum pada jari dengan lanset kemudian darah diperiksa dengan glukometer. Dari 56 warga teridentifikasi melalui pemeriksaan dan wawancara terdapat 42 orang yang menderita DM.

\begin{tabular}{ccc} 
Tabel 1. Karakteristik Responden & Berdasarkan Umu \\
\hline Umur & $\mathbf{n}$ & $\mathbf{\%}$ \\
\hline $40-50$ tahun & 6 & 14 \\
$51-60$ tahun & 32 & 76 \\
61-70 tahun & 4 & 10 \\
Total & $\mathbf{4 2}$ & $\mathbf{1 0 0}$ \\
\hline
\end{tabular}

Sumber: Data Primer 2021

Dari Tabel 1 dapat diketahui mayoritas responden paling banyak umur 51-60 tahun dengan jumlah 32 orang (76\%), umur 40-50 tahun sebanyak 6 orang (14\%), dan umur 61-70 tahun sebanyak 4 orang (10\%). Peningkatan risiko DM sesuai dengan umur, khususnya pada umur lebih dari 40 tahun, karena pada usia tersebut mulai terjadi peningkatan intoleransi glukosa. Adanya proses penuaan menyebabkan berkurangnya kemampuan sel $\beta$ pancreas dalam memproduksi insulin (Nuraeni \& Arjita, 2019).

Tabel 2. Karakteristik Responden Berdasarkan Jenis Kelamin

\begin{tabular}{ccc}
\hline Jenis Kelamin & n & $\mathbf{\%}$ \\
\hline Laki-laki & 17 & 40 \\
Perempuan & 25 & 60 \\
Total & $\mathbf{4 2}$ & $\mathbf{1 0 0}$ \\
\hline
\end{tabular}

Sumber: Data Primer 2021

Tabel 2 menunjukkan bahwa mayoritas responden paling banyak adalah berjenis kelamin perempuan dengan jumlah 25 orang (60\%), jenis kelamin laki-laki sejumlah 17 orang (40\%). Hasil ini sesuai dengan teori yang kemukakan oleh Pratiwi et al (2020) bahwa kejadian DM lebih tinggi pada wanita dibanding pria. Hal ini disebabkan oleh penurunan hormon estrogen akibat menopause. Menurut Suhatridjas (2020) estrogen pada dasarnya berfungsi untuk menjaga keseimbangan kadar gula darah dan meningkatkan penyimpanan lemak serta progesteron yang berfungsi untuk menormalkan kadar gula darah dan membantu menggunakan lemak sebagai energi. 


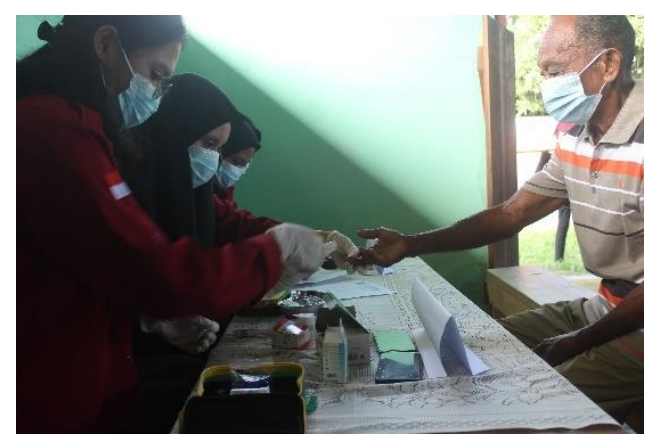

Gambar 3. Kegiatan Screening DM

\subsection{Kegiatan Edukasi Kesehatan}

Pemberian edukasi ini dilaksanakan dengan pemberian materi melalui ceramah dan diskusi serta pembagian leaflet. Dilanjutkan dengan praktik latihan jasmani berupa senam kaki diabetik.

Proses evaluasi (pre test dan post test) pada seluruh peserta menggunakan lembar pernyataan yang harus diisi oleh peserta kegiatan. Soal pre dan post test tersebut untuk mengetahui pengetahuan penderita DM terhadap manajemen diet DM yaitu meliputi pemahaman tentang tujuan dan perencanaan tindakan yang berkaitan dengan perilaku diet, informasi dasar tentang makanan sehat (gizi seimbang) dan jenis-jenis diet, perhitungan kalori dan pola diet sehat atau perencanaan makan.

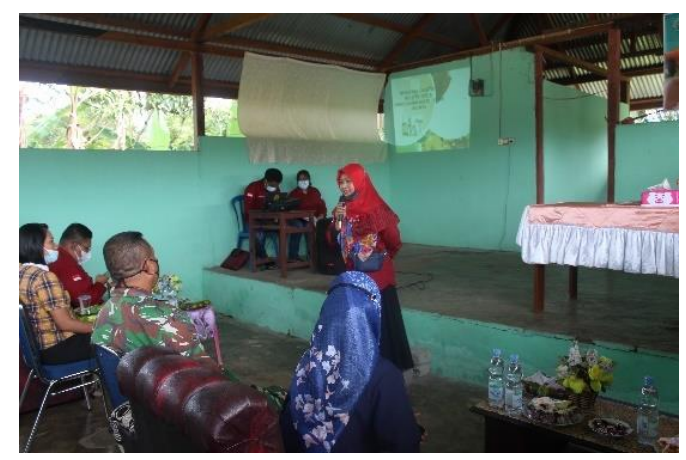

Gambar 4. Kegiatan Edukasi Kesehatan

Berdasarkan Tabel 3 dapat dilihat bahwa hasil pre test 10 pertanyaan para peserta sebelum diberikan informasi atau penjelasan menunjukkan 42 orang dari peserta $(100 \%)$ memperoleh nilai mayoritas peserta memiliki nilai 50 sejumlah 17 orang (40\%). Tabel 4 menunjukan bahwa pada post test terdapat 16 orang (38\%) yang memiliki nilai 60 dengan nilai tertinggi adalah 100 (menjawab soal $100 \%$ benar) sejumlah 1 orang.

Tabel 3 dan 4 menunjukan bahwa terjadi peningkatan pengetahuan yang signifikan. Hasil ini mendukung penelitian Suriani (2018) yang menyatakan bahwa penderita yang menerima intervensi edukasi menimbulkan manajemen DM yang lebih baik. Manajemen DM tersebut termasuk pengetahuan dan perilaku patuh terhadap diet. Ketika penderita menerima pembelajaran penderita memiliki kemampuan dan tahu bagaimana cara manajemen penyakit.

Tabel 3. Hasil Pre Test Pengetahuan Penderita DM tentang Manajemen Diet DM

\begin{tabular}{ccc}
\hline Nilai Pre Test & Jumlah & $\mathbf{\%}$ \\
\hline 40 & 10 & 24 \\
50 & 17 & 40 \\
60 & 15 & 36 \\
Total & $\mathbf{4 2}$ & $\mathbf{1 0 0}$ \\
\hline
\end{tabular}

Sumber: Data Primer 2021 
Tabel 4. Hasil Post Test Pengetahuan Penderita DM tentang Manajemen Diet DM

\begin{tabular}{ccc}
\hline Nilai Post Test & Jumlah & $\mathbf{\%}$ \\
\hline 50 & 1 & 2 \\
\hline 60 & 16 & 38 \\
\hline 70 & 12 & 29 \\
\hline 80 & 9 & 22 \\
\hline 90 & 3 & 7 \\
\hline 100 & 1 & 2 \\
\hline Total & $\mathbf{4 2}$ & $\mathbf{1 0 0}$ \\
\hline
\end{tabular}

Sumber: Data Primer 2021

Pemahaman tentang diet dimiliki oleh penderita DM untuk keberhasilan pengobatan secara mandiri, karena diet merupakan pengoabatan paling utama sebelum olahraga dan obatobatan. Maka dari itu pengetahuan penderita tentang penatalaksanaan penyakitnya terutama dalam manjalani program diet DM harus ditekankan karena faktor ketidakpatuhan dan ketidakpahaman pangkal menuju komplikasi (Keswara, 2019).

Menurut Prabawati et al (2021) metode penyuluhan merupakan salah satu faktor yang mempengaruhi tercapainya suatu hasil penyuluhan secara optimal. Dalam penyuluhan kesehatan metode ceramah lebih efektif digunakan untuk membina perilaku baru atau seseorang yang telah mulai tertarik pada suatu perubahan perilaku atau inovasi.

\subsection{Pelatihan Senam Kaki Diabetik}

Tahap selanjutnya dilakukan pelatihan senam kaki diabetik. Pelatihan tersebut menggunaakn alat peraga yaitu berupa video dan peragaan gerakan langsung oleh instruktur. Mengajarkan senam kaki sesuai dengan standar operasional prosedur. Senam kaki dilakukan dengan menggunakan alat berupa kursi untuk tempat duduk peserta dan koran bekas. Senam kaki dilaksanakan selama 30-45 menit.

Tabel 5. Karakteristik Gula Darah Penderita DM Sebelum Melakukan Senam Kaki Diabetik

\begin{tabular}{ccc}
\hline $\begin{array}{c}\text { Gula Darah Sebelum } \\
\text { Senam Kaki }\end{array}$ & n & \% \\
\hline $150-199 \mathrm{mg} / \mathrm{dl}$ & 0 & 0 \\
$\geq 200 \mathrm{mg} / \mathrm{dl}$ & 42 & 100 \\
Total & $\mathbf{4 2}$ & $\mathbf{1 0 0}$ \\
\hline
\end{tabular}

Sumber: Data Primer 2021

Tabel di atas dapat diketahui bahwa kadar gula seluruh penderita sebelum melakukan senam kaki adalah $\geq 200 \mathrm{mg} / \mathrm{dl}$. Kadar gula darah yang relatif tinggi ini dipengaruhi oleh beberapa faktor diantaranya pola diet dan aktivitas, sesuai teori yang dikemukakan oleh Putri \& Nugroho (2020) bahwa faktor pencetus terjadinya peningkatan kadar gula darah merupakan akibat dari gaya hidup yang salah dan kurangnya aktivitas fisik.

Setelah melakukan senam kaki diabetik penderita dilakukan post test pemeriksaan kembali gula darah sewaktu setelah dua minggu berlalu.

Tabel 6. Karakteristik Gula Darah Penderita DM Sesudah Melakukan Senam Kaki Diabetik

\begin{tabular}{ccc}
\hline $\begin{array}{c}\text { Gula Darah Sesudah } \\
\text { Senam Kaki }\end{array}$ & $\mathbf{n}$ & $\mathbf{\%}$ \\
\hline $150-199 \mathrm{mg} / \mathrm{dl}$ & 33 & 79 \\
$\geq 200 \mathrm{mg} / \mathrm{dl}$ & 9 & 21 \\
Total & $\mathbf{4 2}$ & $\mathbf{1 0 0}$ \\
\hline
\end{tabular}

Sumber: Data Primer 2021

Tabel 6 menunjukkan bahwa mayoritas kadar gula darah penderita sesudah melakukan 
senam kaki 150-199 mg/dl berjumlah 33 orang (79\%) dan kadar gula darah $\geq 200 \mathrm{mg} / \mathrm{dl}$ berjumlah 9 orang (21\%). Hal ini menggambarkan bahwa ke-33 penderita yang melakukan senam kaki dengan baik dan benar secara teratur relatif memiliki kadar gula darah $<200 \mathrm{mg} / \mathrm{dl}$. Nilai kadar gula darah yang lebih rendah atau turun ini menggambarkan terjadinya perbaikan nilai kadar gula darah setelah melakukan senam kaki. Sesuai dengan pendapat yang dikemukakan oleh Haskas (2018) bahwa pada saat latihan (senam) kebutuhan energi meningkat sehingga otot menjadi lebih aktif dan terjadi peningkatan pemakaian glukosa sehingga terjadi penurunan kadar gula darah, hal ini juga dilatarbelakangi oleh faktor kontinuitas atau keteraturan pasien dalam mengikuti senam sehingga terjadi penurunan kadar gula darah. Olahraga atau latihan fisik merupakan bagian yang tidak dapat dipisahkan dari perawatan penderita DM disamping mentaati diet (terapi nutrisi medik), dan pemakaian obat-obatan baik penderita DM tipe 1, maupun tipe 2 . Sembilan penderita DM lainnya yang kadar gulanya masih $\geq 200 \mathrm{mg} / \mathrm{dl}, 4$ orang diantaranya kadar gulanya turun tetapi masih $>200 \mathrm{mg} / \mathrm{dl}$, sedangkan 3 orang lainnya kadar gulanya tetap tidak naik ataupun turun, dan 2 orang sisanya kadar gulanya mengalami peningkatan. Hal ini disebabkan oleh faktor usia, pola diet, dan motivasi.

\section{KESIMPULAN}

Dari hasil edukasi kesehatan yang didapatkan bahwa sebagian peserta sudah mengetahui manajemen diet DM dan latihan senam kaki diabetik. Kegiatan berjalan dengan baik, peserta aktif selama kegiatan berlangsung dan mendengarkan dengan seksama saat pemateri menyampaikan materi. Dampak dari kegiatan ini yaitu peserta sangat antusias dalam mengikuti kegiatan dan dapat mensimulasikan dengan baik mengenai manajemen diet DM dan dapat menerapkan senam kaki diabetik secara rutin. Penderita dilakukan post test pemeriksaan kembali gula darah sewaktu setelah dua minggu berlalu. Mayoritas kadar gula darah penderita sesudah melakukan senam kaki 150-199 mg/dl berjumlah 33 orang (79\%) dan kadar gula darah $\geq 200 \mathrm{mg} / \mathrm{dl}$ berjumlah 9 orang (21\%). Hal ini menggambarkan bahwa ke-33 penderita yang melakukan senam kaki dengan baik dan benar secara teratur relatif memiliki kadar gula darah $<200 \mathrm{mg} / \mathrm{dl}$. Nilai kadar gula darah yang lebih rendah atau turun ini menggambarkan terjadinya perbaikan nilai kadar gula darah setelah melakukan senam kaki.

\section{DAFTAR PUSTAKA}

Ekawati Sutikno, Destya Ika Sriwardani, R. A. R. (2018). Penyuluhan, Skrining, Dan Konsultasi Penyakit Diabetes Mellitus Di Desa Sambirejo, Kabupaten Kediri. Senias, 12-16.

Haskas, Y. (2018). Pelatihan Pengelolaan Makan Dengan 3J Pada Penderita Dm Beserta Keluarganya Di Kecamatan Simbang Kabupaten Maros. Jurnal Dedikasi Masyarakat, 2(1), 1116.

Kemenkes RI. (2018). Laporan Riskesdas Provinsi Maluku Tahun 2018.

Keswara. (2019). Pendidikan Kesehatan Terapi Komplementer Senam Kaki Diabetik Pada Lansia di Panti Sosial Lanjut Usia Tresna Werdha Natar, Lampung Selatan. Jurnal Kreativitas Pengabdian Kepada Masyarakat, 2(1), 101-104.

Nuraeni, N., \& Arjita, I. P. D. (2019). Pengaruh Senam Kaki Diabet Terhadap Penurunan Kadar Gula Darah Pada Penderita Diabetes Mellitus Type II. Jurnal Kedokteran, 3(2), 618-627.

Prabawati, D., Sari, P., \& Neonbeni, Y. (2021). Pendidikan Kesehatan Tentang Perawatan Dan Senam Kaki Pada Pasien Diabetes. SELAPARANG Jurnal Pengabdian Masyarakat Berkemajuan, 4(3), 624-630.

Pratiwi, I. N., Dewi, L. C., \& Widyawati, I. Y. (2020). Buerger Exercise dan Edukasi Perawatan Kaki Pada Penderita Diabetes dan Hipertensi Dalam Upaya Menurunkan Resiko Gangguan Vaskular. Transformasi: Jurnal Pengabdian Masyarakat, 16(2), 121-132.

Putri, D. S., \& Nugroho, E. G. Z. (2020). Senam Kaki Diabetik Sebagai Upaya Peningkatan Self Care 
Pada Pasien Diabetes Mellitus Di Rumah Sakit Mardi Rahayu Kudus. Jurnal Pengabdian Kesehatan, 3(2), 132-140.

Rahmita. (2020). Upaya Peningkatan Keadaran Masyarakat Dalam Pencegahan Penyakit Diabetes Melitus di Desa Pisangan Jaya, Kabupaten Tangerang. Jurnal Pengabdian Masyarakat Multidisiplin, 4(1), 76-81.

Ruben, G., Rottie, J., \& Karundeng, M. (2016). Pengaruh Senam Kaki Diabetes Terhadap Perubahan Kadar Gula Darah Pada Pasien Diabetes Melitus Tipe 2 Di Wilayah Kerja Puskesmas Enemawira. Jurnal Keperawatan UNSRAT, 4(1), 1-5.

Suhatridjas. (2020). Sosialisasi Dan Deteksi Dini Diabetes Mellitus Sebagai Upaya Pencegahan Komplikasi. Jurnal Kreativitas Pengabdian Masyarakat (PKM), 3(2), 323-330.

Suriani. (2018). Penyuluhan dan Pendampingan Senam Kaki Diabetes pada Penderita Diabetes Melitus di Desa Bukit Hagu Kecamatan Lhoksukon Kabupaten Aceh Utara. Sekolah Tinggi Ilmu Kesehatan Getsempena Lhoksukon.

Trijayanti. (2019). Pengaruh Senam Kaki Terhadap Perubahan Kadar Gula Darah Pada Lansia Penderita Diabetes Mellitus Tipe 2 di Posyandu Mawar Desa Balarejo Kecamatan Kebonsari Kabupaten Madiun. STIKes Bhakti Husada Mulia Madiun, 8(5), 55. 